Advances in Dynamical Systems and Applications.

ISSN 0973-5321, Volume 16, Number 1, (2021) pp. 5-15

(C) Research India Publications

https://dx.doi.org/10.37622/ADSA/16.1.2021.5-15

\title{
A Comparison of Survivor Rate Estimates for Some Probability Distribution Models Using Least-Squares Method in Conjunction with Simplex and Quasi- Newton Optimization Methods
}

\author{
Khizar H. Khan \\ Department of Mathematics, College of Science and Humanities, Prince Sattam Bin \\ Abdulaziz University, Al-Kharj, Kingdom of Saudi Arabia.
}

\begin{abstract}
In this paper, we find survival rate estimates, parameter estimates, variance covariance for some probability distribution models like, Exponential, Inverse Gaussian, Gompertz, Gumbels and Weibull distributions using least-squares estimation method. We found these estimates for the case when partial derivatives were not available and for the case when partial derivatives were available. The first case when partial derivatives were not available, we used the simplex optimization (Nelder and Meads ([6],[7]) and Hooke and Jeeves ([4],[5])) methods and the case when first partial derivatives were available we applied the Quasi - Newton optimization (Davidon-Fletcher-Powel (DFP) and the Broyden-Fletcher-Goldfarb-Shanno (BFGS) methods. The medical data sets of 21 Leukemia cancer patients with time span of 35 weeks ([3]) were used.
\end{abstract}

Keywords: Exponential, Inverse Gaussian, Gompertz, Gumbel and Weibull distribution models, Nelder and Mead, Hooke and Jeeves, DFP and BFGS optimization methods, Parameter estimation, Least Square method, KaplanMeier estimates, Parameter estimates, Survival rate Estimates, VarianceCovariance Matrix.

\section{INTRODUCTION}

The method of linear least-squares requires that a straight line be fitted to a set of data points such that the sum of squares of the vertical deviations from the points to be minimized ([1],[2]). 
The objective function is a sum of squared residuals - the term 'least-squares' derives from the function:

$$
F=\sum_{i=1}^{m} r_{i}^{2}=\sum_{i=1}^{m}\left(y_{i}^{o b s}-y_{i}^{e s t}\right)^{2}
$$

Where $\quad r_{i}=y_{i}^{o b s}-y_{i}^{e s t}, i=1,2, \cdots, m$, is a residual vector.

The objective function is the sum of the squares of the deviations between the observed values and the corresponding estimated values ([1],[2],[9]]). The maximum absolute discrepancy between observed and estimated values is minimized using optimization methods.

We treated Kaplan-Meier estimates $\left(K M\left(t_{i}\right)\right)([20],[3])$ as the observed values $\left(y_{i}^{o b s}\right)$ of the objective function and the survivor rate estimates $\left(S\left(t_{i}\right)\right)$ of some distribution models as the estimated value $\left(y_{i}^{e s t}\right)$ of the objective function $F$. We considered the objective function for the models of the form

$$
F(t, a, b)=\sum_{i=1}^{m} f_{i}\left(K M\left(t_{i}\right)-S\left(t_{i}, a, b\right)\right)^{2}
$$

where $f_{i}$ is the number of failures at time $t_{i}$ and $m$ is the number of failure groups.

We find numerical value of the function at initial point $\left(a_{0}, b_{0}\right)$ and is used in numerical optimization search methods to find the minimum point $\left(a^{*}, b^{*}\right)$ (parameters estimates).

\section{NUMERICAL RESULTS FOR DIFFERENT PROBABILITY} DISTRIBUTION MODELS USING LEAST-SQUARES METHOD AND APPLYING NELDER AND MEADS AND HOOKE AND JEEVES OPTIMIZATION SEARCH METHODS

Table 1: Parameter Estimates and Optimal Function Value for the Exponential, Inverse Gaussian, Gompertz, Gumbel and Weibull Distribution Models using Nelder and Meads, and Hooke and Jeeves methods.

\begin{tabular}{|c|c|c|c|c|c|}
\hline & \multicolumn{5}{|c|}{ Nelder and Meads Method } \\
\hline & Exponential & $\begin{array}{c}\text { Inverse- } \\
\text { Gaussian }\end{array}$ & $\begin{array}{c}\text { Gompertz } \\
\text { Model }\end{array}$ & $\begin{array}{c}\text { Gumbel } \\
\text { Model }\end{array}$ & Weibull \\
\hline $\begin{array}{c}\text { Parameters } \\
\text { Estimates }\end{array}$ & $3.14283 \mathrm{E}-02$ & 0.31317817 & 0.020989099 & 0.079469520 & 30.00336 \\
\hline $\begin{array}{c}\text { Optimal } \\
\text { Functional } \\
\text { value }\end{array}$ & $3.71878 \mathrm{E}-03$ & 0.01823842 & 0.037910900 & 0.009399999 & 1.203254 \\
\hline
\end{tabular}




\begin{tabular}{|c|c|c|c|c|c|}
\hline & \multicolumn{5}{|c|}{ Hooke and Jeeves Method } \\
\hline & Exponential & $\begin{array}{c}\text { Inverse- } \\
\text { Gaussian }\end{array}$ & $\begin{array}{c}\text { Gompertz } \\
\text { Model }\end{array}$ & $\begin{array}{c}\text { Gumbel } \\
\text { Model }\end{array}$ & Weibull \\
\hline $\begin{array}{c}\text { Parameters } \\
\text { Estimates }\end{array}$ & $3.14389 \mathrm{E}-02$ & 0.419982779 & 0.031560815 & 0.08008377 & 26.60585 \\
& 0.219999999 & 0.045794945 & 0.00934490 & 1.496967 \\
\hline $\begin{array}{c}\text { Optimal } \\
\text { Functional } \\
\text { value }\end{array}$ & $3.70689 \mathrm{E}-03$ & 0.04643498 & 0.03664972 & 0.03094435 & 0.066557 \\
\hline
\end{tabular}

Table 2: Comparison of Survival Rate estimates for the Exponential, Inverse Gaussian, Gompertz, Gumbel and Weibull Distribution Models using Nelder and Meads, and Hooke and Jeeves methods.

\begin{tabular}{|c|c|c|c|c|c|c|c|}
\hline \multirow{2}{*}{$\begin{array}{c}\text { Failure } \\
\text { Time } \\
\text { (Weeks) }\end{array}$} & \multirow{2}{*}{$\begin{array}{c}\text { Number } \\
\text { of } \\
\text { Failures }\end{array}$} & \multicolumn{6}{|c|}{ Nelder and Meads Method } \\
\hline & & Exponential & $\begin{array}{l}\text { Inverse- } \\
\text { Gaussian }\end{array}$ & \begin{tabular}{|c} 
Gompertz \\
Model
\end{tabular} & \begin{tabular}{|c|} 
Gumbel \\
Model
\end{tabular} & Weibull & \begin{tabular}{|c|} 
Kaplan \\
Meier
\end{tabular} \\
\hline 0 & 1 & 1 & 1 & 1 & 1 & 1 & 1 \\
\hline 6 & 3 & 0.828142 & 0.877412 & 0.86616 & 0.828057 & 0.86573 & 0.85714 \\
\hline 7 & 1 & 0.802520 & 0.841704 & 0.84333 & 0.815132 & 0.84066 & 0.80722 \\
\hline 10 & 1 & 0.7303127 & 0.744553 & 0.77433 & 0.771117 & 0.76598 & 0.75294 \\
\hline 13 & 1 & 0.66460169 & 0.664633 & 0.70497 & 0.718565 & 0.69381 & 0.69019 \\
\hline 16 & 1 & 0.60480320 & 0.599291 & 0.63587 & 0.656881 & 0.62543 & 0.62745 \\
\hline 22 & 1 & 0.50086347 & 0.499796 & 0.50116 & 0.506870 & 0.50236 & 0.53815 \\
\hline 23 & 1 & 0.4853670 & 0.486228 & 0.47947 & 0.478952 & 0.48371 & 0.44817 \\
\hline
\end{tabular}

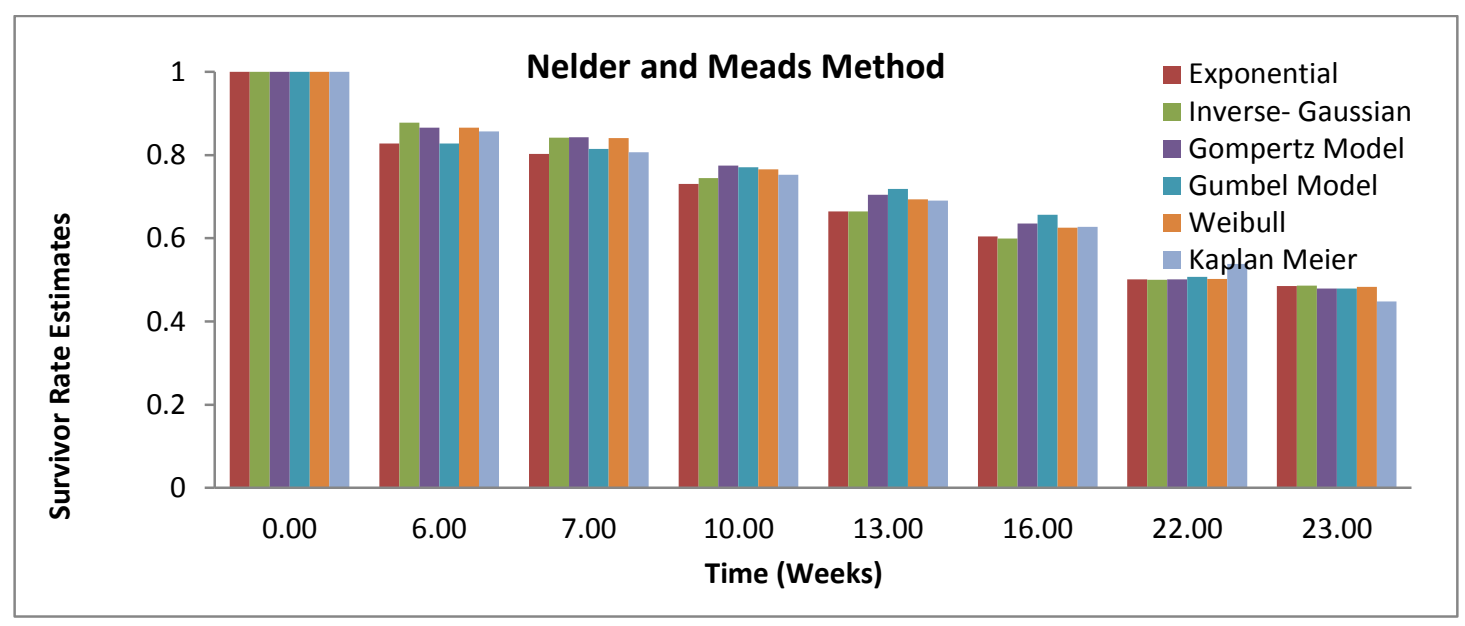




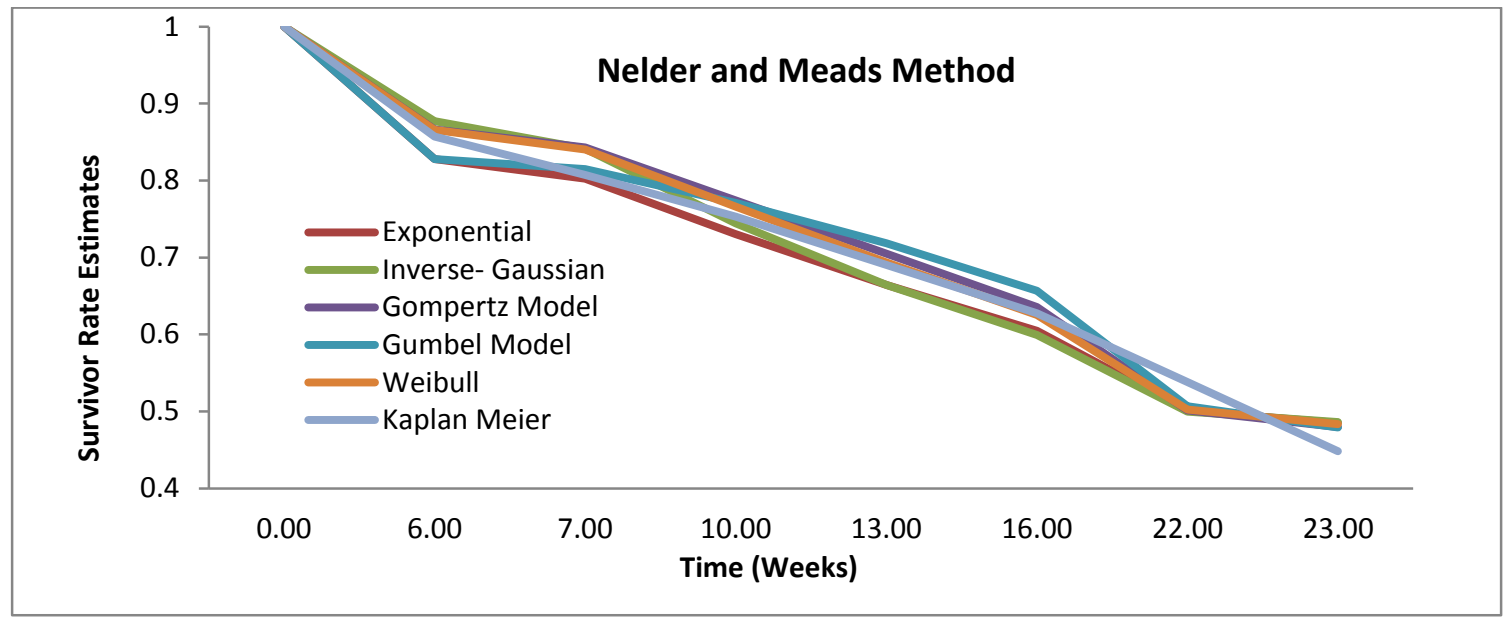

Table 3: Comparison of Survival Rate estimates Using Nelder and Meads, and Hooke and Jeeves Optimization methods

\begin{tabular}{|c|c|c|c|c|c|c|c|}
\hline Failure & \multirow{2}{*}{$\begin{array}{c}\text { Number } \\
\text { of } \\
\text { (Weeks) }\end{array}$} & \multicolumn{6}{|c|}{ Hooke and Jeeves Method } \\
\cline { 3 - 8 } & Failures & Exponential & $\begin{array}{c}\text { Inverse- } \\
\text { Gaussian }\end{array}$ & $\begin{array}{c}\text { Gompertz } \\
\text { Model }\end{array}$ & $\begin{array}{c}\text { Gumbel } \\
\text { Model }\end{array}$ & Weibull & $\begin{array}{c}\text { Kaplan } \\
\text { Meier }\end{array}$ \\
\hline 0 & 1 & 1 & 1 & 1 & 1 & 1 & 1 \\
\hline 6 & 3 & 0.8280900 & 0.888879 & 0.8544705 & 0.826505 & 0.89801 & 0.85714 \\
\hline 7 & 1 & 0.8024607 & 0.853157 & 0.8307175 & 0.813581 & 0.87327 & 0.80722 \\
\hline 10 & 1 & 0.7302349 & 0.753023 & 0.7605747 & 0.769623 & 0.79365 & 0.75294 \\
\hline 13 & 1 & 0.6645097 & 0.668558 & 0.6923736 & 0.717234 & 0.71014 & 0.69019 \\
\hline 16 & 1 & 0.6047002 & 0.598642 & 0.6264513 & 0.655845 & 0.62683 & 0.62745 \\
\hline 22 & 1 & 0.5007462 & 0.49138 & 0.5027187 & 0.506848 & 0.47125 & 0.53815 \\
\hline 23 & 1 & 0.4852482 & 0.476720 & 0.4832757 & 0.479145 & 0.44748 & 0.44817 \\
\hline
\end{tabular}

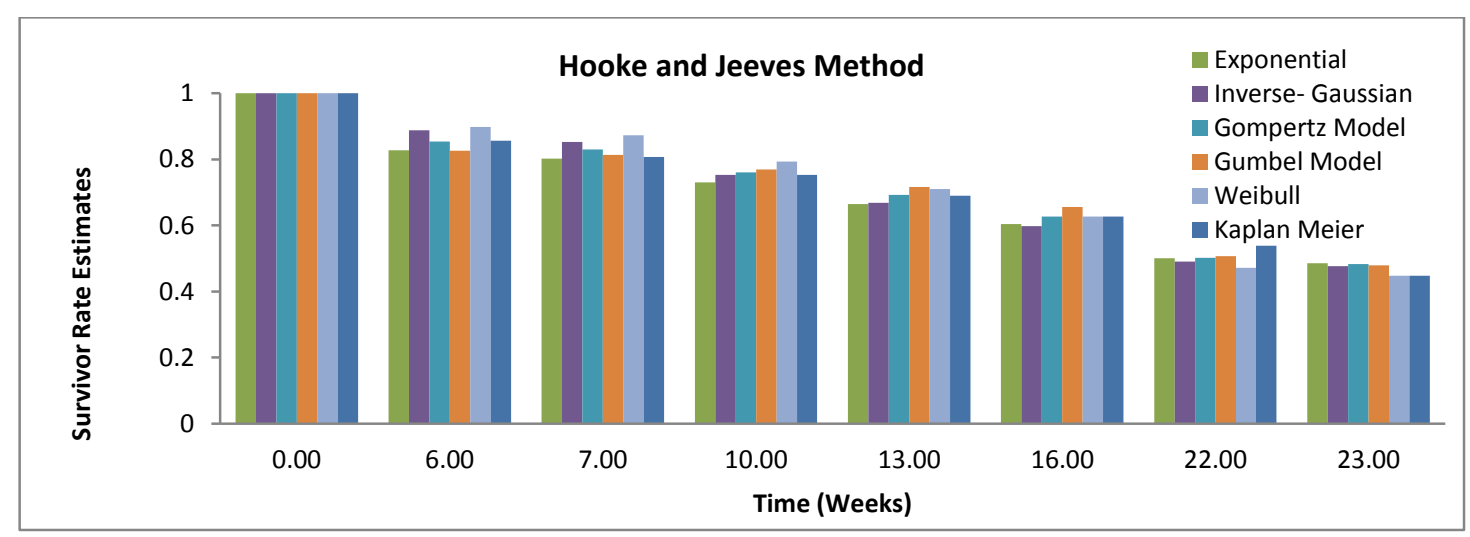




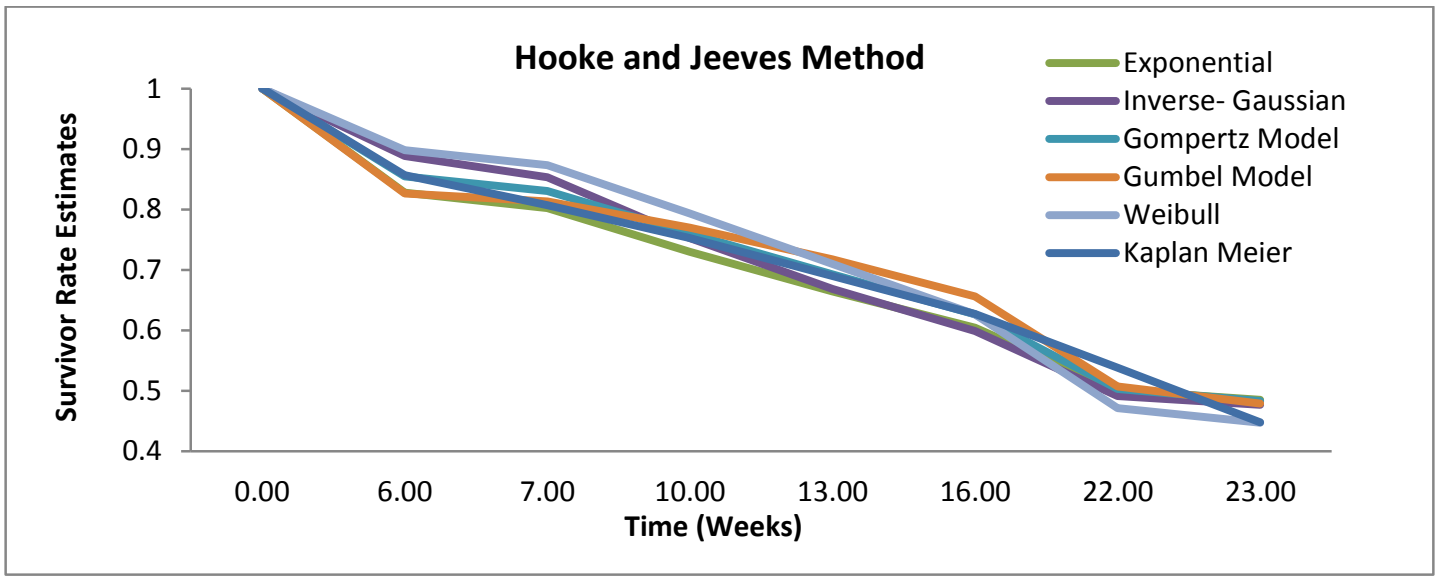

\section{PROBABILITY DISTRIBUTION MODELS USING LEAST-SQUARES METHODS AND APPLYING QUASI-NEWTON METHODS (DFP AND BFGS METHODS)}

For a practical application of the least-squares estimation method, when partial derivatives of the objective function $F$ are available. We used Davidon-FletcherReeves (DFP), ([13,14]) and Broyden-Fletcher and Shanno (BFGS), ([9.14,15]), methods to find the parameter estimates and survivor rate estimates for different probability distribution models.

\subsection{Exponential Distribution Model}

The exponential distribution ([22]) is a very commonly used distribution in reliability and life testing. The single-parameter exponential pdf is

$$
f(t)=\lambda \exp (-\lambda t), t \geq 0, \lambda>0
$$

The reliability (or survivor) function of the exponential distribution is

$$
\begin{aligned}
& S(t)=1-F(t)=1-\int_{0}^{t} f(x) d x \\
& \text { Or } S(t)=\exp (-\lambda t) . \\
& H(t)=\frac{f(t)}{S(t)}=\lambda
\end{aligned}
$$

Where $\lambda$ parameter is the constant failure rate (or hazard rate). To apply these optimization methods, we need to find the first partial derivatives of the objective function $F$ of eq. (1.3).

$\frac{\partial F}{\partial \lambda}=2 \sum_{i=1}^{m} f_{i}\left(S\left(t_{i}\right)-K M\left(t_{i}\right)\right) \frac{\partial S\left(t_{i}\right)}{\partial \lambda}$, where $\frac{\partial S(t)}{\partial \lambda}=-t S(t)$. 


\subsection{Inverse Gaussian Distribution Model}

The pdf for the Inverse Gaussian distribution, $f(t)=\frac{1}{\sqrt{2 \pi \beta t^{3}}} d \exp \left(-\frac{(d-v t)^{2}}{2 \beta t}\right)$,

$$
\text { or } f(t)=\sqrt{\frac{\kappa}{2 \pi \rho t^{3}}} \exp \left[-\frac{\kappa}{2 \rho t}\left\{(\rho t-1)^{2}\right\}\right] \text {, where } t>0, \kappa=\frac{d^{2} \rho}{\beta}, \rho=\frac{v}{d},
$$

The survivor function for the inverse Gaussian distribution model $([16,17])$ at time $t_{i}$ is $S(t)=\Phi\left(-\sqrt{\frac{\kappa}{\rho \mathrm{t}}}(\rho t-1)\right)-\mathrm{e}^{2 \kappa} \Phi\left(-\sqrt{\frac{\kappa}{\rho \mathrm{t}}}(\rho t+1)\right)$, where $\Phi$ is the standard normal distribution function and $S\left(t_{i}, \alpha_{0}, \beta_{0}\right)$ is the survivor function ([17]) at the starting point $\left(\alpha_{0}, \beta_{0}\right)$.

\subsection{Gompertz Distribution Model}

The survivor function for the two-parameter Gompertz distribution ([13], [15]) is

$$
S(t)=\exp \left(\frac{b}{a}(1-\exp (a t))\right) .
$$

To find the parameter estimates for the Gompertz distribution model using leastsquares estimation procedures, we consider the objective function $F$ as

$$
F=\sum_{i=1}^{m} f_{i}\left(S\left(t_{i}\right)-K M\left(t_{i}\right)\right)^{2}
$$

where $K M(t)$ is the Kaplan-Meier estimate for the failure time $t$.

For the DFP and BFGS optimization methods, we find the first partial derivatives of the objective function $F$, we have

and

$$
\frac{\partial F}{\partial a}=2 \sum_{i=1}^{m} f_{i}\left(S\left(t_{i}\right)-K M\left(t_{i}\right)\right) \frac{\partial S\left(t_{i}\right)}{\partial a}
$$

where

$$
\frac{\partial F}{\partial b}=2 \sum_{i=1}^{m} f_{i}\left(S\left(t_{i}\right)-K M\left(t_{i}\right)\right) \frac{\partial S\left(t_{i}\right)}{\partial b},
$$$$
\frac{\partial S(t)}{\partial a}=-\frac{b}{a^{2}}(1+\exp (a t)(a t-1)) S(t)
$$

and

$$
\frac{\partial S(t)}{\partial b}=\frac{1}{a}(1-\exp (a t)) S(t) .
$$

Using eq.(3.7), eq.(3.8) and eq.(3.9) in the DFP and the BFGS optimization method, we can find the estimated value of the parameters for which the least-squares function gives the minimum value for Gompertz distribution model $([8,9,10])$. 


\subsection{Gumbel Distribution Model}

The survivor function for the two-parameter Gumbel distribution model ([18]) is

$$
S(t)=\exp \left(-\left(\frac{b}{a}\right) \exp (a t)\right) \text {. }
$$

We construct the least-squares estimation function for the Gumbel distribution model

$$
F=\sum_{i=1}^{m} f_{i}\left(S\left(t_{i}\right)-K M\left(t_{i}\right)\right)^{2}
$$

where $K M(t)$ is again the Kaplan-Meier estimate for the failure time $t$.

To find the parameter estimates, we used the DFP and the BFGS optimization methods ([19]-[24]). These optimization methods require only first partial derivatives of the objective function $\mathrm{F}$

$$
\frac{\partial F}{\partial a}=2 \sum_{i=1}^{m} f_{i}\left(S\left(t_{i}\right)-K M\left(t_{i}\right)\right) \frac{\partial S\left(t_{i}\right)}{\partial a}
$$

and

$$
\frac{\partial F}{\partial b}=2 \sum_{i=1}^{m} f_{i}\left(S\left(t_{i}\right)-K M\left(t_{i}\right)\right) \frac{\partial S\left(t_{i}\right)}{\partial b},
$$

where

$$
\frac{\partial S(t)}{\partial a}=\frac{b}{a^{2}} \exp (a t)(1-\exp (a t)) S(t)
$$

and

$$
\frac{\partial S(t)}{\partial b}=-\frac{1}{a} \exp (a t) S(t)
$$

Now using eq.(3.11), eq.(3.12) and eq.(3.13) in the DFP and the BFGS optimization method, we can find the estimated value of the parameters for which the least-squares function gives the minimum value for Gumbel distribution model $([10,11])$.

\subsection{Weibull Distribution Model}

We know that the survivor function for the two-parameter Weibull distribution ([9],

$$
\text { [10]) is } \quad S(t)=\exp \left(-\left(\frac{t}{\alpha}\right)^{\beta}\right) \text {, }
$$

where $\alpha$ is the scale parameter and $\beta$ is the shape parameter. To find the parameter estimates for the Weibull distribution model using least-squares estimation procedures, we consider the objective function $F$ as $F=\sum_{i=1}^{m} f_{i}\left(S\left(t_{i}\right)-K M\left(t_{i}\right)\right)^{2}$

where $K M(t)$ is the Kaplan-Meier estimate for the failure time $t$. 
To apply DFP and BFGS optimization methods, we find first partial derivatives of the objective function $F$, we have

$$
\frac{\partial F}{\partial \alpha}=2 \sum_{i=1}^{m} f_{i}\left(S\left(t_{i}\right)-K M\left(t_{i}\right)\right) \frac{\partial S\left(t_{i}\right)}{\partial \alpha}
$$

and

$$
\frac{\partial F}{\partial \beta}=2 \sum_{i=1}^{m} f_{i}\left(S\left(t_{i}\right)-K M\left(t_{i}\right)\right) \frac{\partial S\left(t_{i}\right)}{\partial \beta},
$$

where

$$
\frac{\partial S(t)}{\partial \alpha}=\left(\frac{\beta}{\alpha}\right)\left(\frac{t}{\alpha}\right)^{\beta} S(t) \text { and } \frac{\partial S(t)}{\partial \alpha}=-\ln \left(\frac{t}{\alpha}\right)\left(\frac{t}{\alpha}\right)^{\beta} S(t) .
$$

Using the objective function eq.(3.15), and the first partial derivatives eq.(3.16) and eq.(3.17) in the DFP and the BFGS optimization method, we can find the estimated value of the parameters for which the least-squares function gives the minimum value for Weibull distribution model $([24,25,26])$.

The numerical results for the above said probability distribution models are presented in the table- 4 and table-5.

Table 4: Parameter Estimates and Optimal Function Values, Gradient and the

\begin{tabular}{|c|c|c|c|c|c|}
\hline & \multicolumn{5}{|c|}{ DFP Method } \\
\hline & Exponential & $\begin{array}{l}\text { Inverse- } \\
\text { Gaussian }\end{array}$ & $\begin{array}{c}\text { Gompertz } \\
\text { Model }\end{array}$ & Gumbel Model & Weibull \\
\hline $\begin{array}{c}\text { Parameter } \\
\text { Estimates } \\
\left(a^{*}, b^{*}\right)\end{array}$ & $2.96463 \mathrm{E}-2$ & $\begin{array}{l}0.18341065 \\
0.01220035\end{array}$ & $\begin{array}{l}0.018866 \\
0.025292\end{array}$ & $\begin{array}{l}0.08415445 \\
0.00930334\end{array}$ & $\begin{array}{c}30.75038 \\
1.12722\end{array}$ \\
\hline $\begin{array}{c}\text { Optimal } \\
\text { Functional } \\
\text { value }\end{array}$ & $5.055 \mathrm{E}-03$ & $0.565086 \mathrm{E}-02$ & 0.003055 & 0.006062 & 0.00321109 \\
\hline $\begin{array}{c}\text { Gradient at } \\
\left(a^{*}, b^{*}\right)\end{array}$ & $9.766 \mathrm{E}-08$ & $\begin{array}{l}-0.63533 \mathrm{E}-05 \\
-0.46768 \mathrm{E}-04\end{array}$ & $\begin{array}{l}0.962 \mathrm{E}-06 \\
0.648 \mathrm{E}-05\end{array}$ & $\begin{array}{l}0.9039 \mathrm{E}-09 \\
0.8884 \mathrm{E}-08\end{array}$ & $\begin{array}{l}-0.2713 \mathrm{E}-05 \\
-0.2142 \mathrm{E}-04\end{array}$ \\
\hline $\begin{array}{c}\text { Variance- } \\
\text { Covariance at } \\
\quad\left(a^{*}, b^{*}\right)\end{array}$ & $8.1389 \mathrm{E}-04$ & $\begin{array}{ll}6.2405 & 0.3346 \\
0.3346 & 0.0181\end{array}$ & $\begin{array}{ll}0.0826 & -0.0186 \\
-0.0186 & .00478\end{array}$ & $\begin{array}{cc}0.022389 & -0.0009 \\
-0.0009 & 0.00012\end{array}$ & $\begin{array}{lr}1737 . & -73.95 \\
-73.95 & 4.27\end{array}$ \\
\hline
\end{tabular}
variance-covariance's for the Exponential, Inverse Gaussian, Gompertz, Gumbel and Weibull Distribution Models using DFP method. 
Table 5: Parameter Estimates and Optimal Function Values, Gradient and the variance-covariance's for the Exponential, Inverse Gaussian, Gompertz, Gumbel and Weibull Distribution Models using BFGS method.

\begin{tabular}{|c|c|c|c|c|c|}
\hline & \multicolumn{5}{|c|}{ BFGS Method } \\
\hline & Exponential & $\begin{array}{l}\text { Inverse- } \\
\text { Gaussian }\end{array}$ & $\begin{array}{l}\text { Gompertz } \\
\text { Model }\end{array}$ & Gumbel Model & Weibull \\
\hline $\begin{array}{c}\text { Parameter } \\
\text { Estimates } \\
\left(a^{*}, b^{*}\right)\end{array}$ & $2.964389 \mathrm{E}-2$ & $\begin{array}{l}0.18346625 \\
0.01220656\end{array}$ & $\begin{array}{l}0.01886325 \\
0.02529981\end{array}$ & $\begin{array}{l}0.08415415 \\
0.00930323\end{array}$ & $\begin{array}{c}30.75490 \\
1.12708\end{array}$ \\
\hline $\begin{array}{c}\text { Optimal } \\
\text { Functional } \\
\text { value }\end{array}$ & $5.055 \mathrm{E}-03$ & $0.56508 \mathrm{E}-02$ & 0.00305524 & 0.00606156998 & 0.00321109491 \\
\hline $\begin{array}{c}\text { Gradient at } \\
\left(a^{*}, b^{*}\right)\end{array}$ & $-1.264 \mathrm{E}-05$ & $\begin{array}{c}-0.271 \mathrm{E}-06 \\
0.595 \mathrm{E}-05\end{array}$ & $\begin{array}{c}0.9623 \mathrm{E}-06 \\
0.64881 \mathrm{E}-05\end{array}$ & $\begin{array}{l}-0.12160 \mathrm{E}-07 \\
-0.23565 \mathrm{E}-07\end{array}$ & $\begin{array}{l}0.10014 \mathrm{E}-07 \\
0.16052 \mathrm{E}-05\end{array}$ \\
\hline $\begin{array}{c}\text { Variance- } \\
\text { Covariance } \\
\text { at }\left(a^{*}, b^{*}\right)\end{array}$ & $8.1396 \mathrm{E}-04$ & $\begin{array}{ll}6.0991 & 0.3257 \\
0.3257 & 0.0175\end{array}$ & $\begin{array}{lr}0.0842 & -0.0187 \\
-0.0187 & 0.0048\end{array}$ & $\begin{array}{cc}0.0211 & -0.0009 \\
-0.0009 & 0.00012\end{array}$ & $\begin{array}{cc}2253.58 & -83.71 \\
-83.71 & 4.46\end{array}$ \\
\hline
\end{tabular}

\section{CONCLUSION}

The Survival rate estimates for the 21 Leukemia patients for the period of 35 week under observations were compared using parametric distribution models and nonparametric Kaplan Meier Model ([1]). We found that the results for the distribution models were approximately same for both the cases when the derivatives of an objective function were not available (Using the Hooke and Jeeves, and Nelder and Meads method) and when first partial derivatives of the objective function were available (using Quasi-Newton method (DFP and BFGS methods)) and are also comparable with the non-parametric model. For the parametric models like (Exponential, Gompertz, Gumbel, Inverse and Weibull), we can find the parametric estimate, variance - covariance, optimal function values and some other useful information in different tables and graphical representations.

\section{ACKNOWLEDGEMENT}

The author (Khizar H. Khan) thankfully acknowledges the support provided by the Department of Mathematics, College of Science and Humanities, Prince Sattam Bin Abdulaziz University, Al-Kharj, (Riyadh) and Ministry of Higher Education, Saudi Arabia, for providing the facilities and an environment to perform this research work. 


\section{REFEENCES}

[1]. Plackett, R.L. (1972). "The discovery of the method of least squares. Biometrika", 59,239-251.

[2]. J.E. Dennis Jr., R.B. Schnabel. "Nonlinear least squares Numerical Methods for Unconstrained Optimization and Nonlinear Equations", SIAM, Philadelphia, PA (1996), pp. 218-238.

[3]. Cox D.R.,Oaks D. (1984) Analysis of Survival Data. London Chapman and Hall.

[4]. Robert Hooke and T.A. Jeeves, Westinghouse Research Laboratories, Piitsburgh, Pennsylvania, "Direct Research Solution of Numerical and statistical Problem research", International Journal of Statistics, Vol.16, pp.670-683,1960.

[5]. G.S Kirat, A.N Surde "Review of Hooke and Jeeves Direct Search Solution Method Analysis Applicable To Mechanical Design Engineering" Novateur Publications International Journal of Innovations in Engineering Research and Technology [IJIERT], ISSN: 2394-3696, Volume 1, Issue 2, Dec-2014.

[6]. J.A. Nelder, R. Mead, "A Simplex method for function minimization", Computer Journal 7, (1965), 308-313.

[7]. F. Gao, L. Han, "Implementing the Nelder-Mead Simplex Algorithm with Adaptive Parameters", Comput. Optim. Appl, vol., no. , pp. , 4th May 2010.

[8]. J. Wu, W. Hung, C. Tsai "Estimation of parameters of the Gompertz distribution using the least squares method", Appl. Math. Comput., 158 (2004), pp. 133147.

[9]. Fernando Jiménez Torres. "Estimation of parameters of the shifted Gompertz distribution using least squares, maximum likelihood and moments methods", Journal of Computational and Applied Mathematics. Volume 255, 1 January 2014, Pages 867-877

[10]. Khizar H. Khan (2017) "Parameter Estimation for the Gompertz and Gumbel Distribution Models Using Least-Squares Method in Conjunction with Simplex and quasi-Newton Optimization Methods" ,World Applied Sciences Journal 35 (3): 465-469, 2017, ISSN 1818-4952.

[11]. Mahdi, Smail; Cenac, Myrtene. "Estimating Parameters of Gumbel Distribution using the Methods of Moments, probability weighted Moments and maximum likelihood", Revista de Matemática: Teoríay Aplicaciones, vol. 12, núm. 1-2, 2005, pp. 151-156 Universidad de Costa Rica San José, Costa Rica.

[12]. Fletcher, R. (1970), "A New Approach to Variable Metric Algorithms", Computer Journal, 13 (3): 317-322.

[13]. Fletcher, R. and Powell, M. J. D. A Rapidly Convergent Descent Method for Minimization. Computer J. , vol. 6, Apr . 1963-Jan. 1964, pp . 163-168. 
[14]. Fletcher, Roger (1987), Practical methods of optimization (2nd ed.), New York: John Wiley \& Sons, ISBN 978-0-471-91547-8.

[15]. Shanno, David F.; Kettler, Paul C. (July 1970), "Optimal conditioning of quasiNewton methods", Mathematics of Computation, 24 (111): 657-664.

[16]. J. L. Folks and R. S. Chhikara", The Inverse Gaussian Distribution and Its Statistical Application--A Review" Journal of the Royal Statistical Society. Series B (Methodological), Vol. 40, No. 3, pp. 263-289 (1978).

[17]. Khan, K. H. (2018) Parameter Estimation with Least-Squares Method for the Inverse Gaussian distribution Model Using Simplex and Quasi-Newton Optimization Methods. Journal of Applied Mathematics and Computation, 2(10), 466-472. DOI: 10.26855/jamc.2018.10.002.

[18]. Zhenlin Yang, "Maximum Likelihood Predictive Densities for the Inverse Gaussian Distribution with Applications to Reliability and Lifetime Predictions", Microelectronics Reliability, 39, 1413-1421, 1999.

[19]. Freireich et al. (1963 "The Effect of 6-mercaptopurine on the duration of steroid induced remission in acute leukemia", Blood 21), pp. 699-716.

[20]. Goldfarb, D. (1970), "A Family of Variable Metric Updates Derived by Variational Means", Mathematics of Computation, 24 (109): 23-26.

[21]. Kaplan E.L., Meier P. (1958). Nonparametric estimation from incomplete observations, J. Amer. Statist. Assoc., 53, pp. 457-481.

[22]. Weibull, W. (1951): A Statistical Distribution of wide Applicability. Journal of Applied Mechanics, 18, 239-296.

[23]. Lawless J.F. (1982) Statistical Models and Methods for life-time Data, John Wiley and Sons.

[24]. Khizar H.Khan and Zafar Mehmud "Weibull distribution Model for the Breast Cancer Survival Data Using Maximum Likelihood Method", Journal of Research (Science), Vol. 10, No. 1\&2, pp-45-49.

[25]. Kantar, Y.M.; ,Seno "glu, B. (2009). “ A comparative study for the location and scale parameters of the Weibull distribution with a given shape parameter". Comput. Geosci. 2008, 34, 1900-1909.

[26]. Altun, A. (2012) "Estimation of the shape parameter of the Weibull distribution using linear regression methods: Non-censored samples". Qual. Reliab. Eng. Int. 2012, 29, 1207-1219. 
